\title{
Summary on Seismic Damage Characteristics of Bottom Frame Structures in Wenchuan Earthquake
}

\author{
Hongyu Deng* \\ College of Space Technology and Civil Engineering \\ Harbin Engineering University \\ Harbin, China \\ E-mail: dengblue@163.com \\ * Corresponding Author
}

\author{
Baitao Sun \\ Earthquake Administration \\ Key Laboratory of Earthquake Engineering and \\ Engineering Vibration of China Earthquake \\ Administration \\ Harbin, China
}

\section{DAMAGE OF FRAME-SHEAR WALL STORIES}

\begin{abstract}
The application of masonry buildings with frame and seismic-wall in the lower stories in the "5.12" Wenchuan earthquake disaster area was very extensive. The main damage characteristic of this kind of structure was summarized through field investigation where a large number of examples appeared. Overall, the seismic damage of the bottom frame structures can be summarized as the following: firstly, if the stiffness of frame shear wall stories is larger, the failure of underlayer is light but the upper masonry stories get seriously damaged; if the stiffness of upper masonry stories are larger, the underlayer gets seriously damaged but the failure of upper masonry stories are light. Secondly, the damage of wall is heavier than the column, the damage of column is heavier than the beam; the damage of column cap is heavier than column base, and the damage of corner column is heavier than inside column and side column. Thirdly, the force of transition layer is complex, and the wall is destroyed seriously. Fourthly, the destruction of the upper part of the bottom frame structure is similar to the structure of the multi-storey masonry structure.
\end{abstract}

Keywords-Bottom Frame Structure; Wenchuan Earthquake; Characteristic of Earthquake Disaster

\section{INTRODUCTION}

Masonry building with frame and seismic-wall in the lower story is a special structure system of masonry structure. For the use function of the large standard width of a room in underlayer, it is a hybrid system with upper masonry stories and frame shear wall stories in underlayer. Compared with masonry structure, there are many similarities between these two structure systems but not quite the same. In the past earthquakes, the seismic damage data of the bottom frame structure is less, and people do not have a clear understanding of the seismic performance of this structure. In the Wenchuan earthquake $^{[1]}$, a large number of bottom frame structures have been destroyed, and the seismic damage data is very rich. To summarize the damage characteristics of bottom frame structures, and compare the similarities and differences of the earthquake disaster characteristics between multistory masonry structure and bottom frame structures, that has important significance on studying the failure mechanism and improving the seismic performance of bottom frame structures.
A. Damage of shear wall

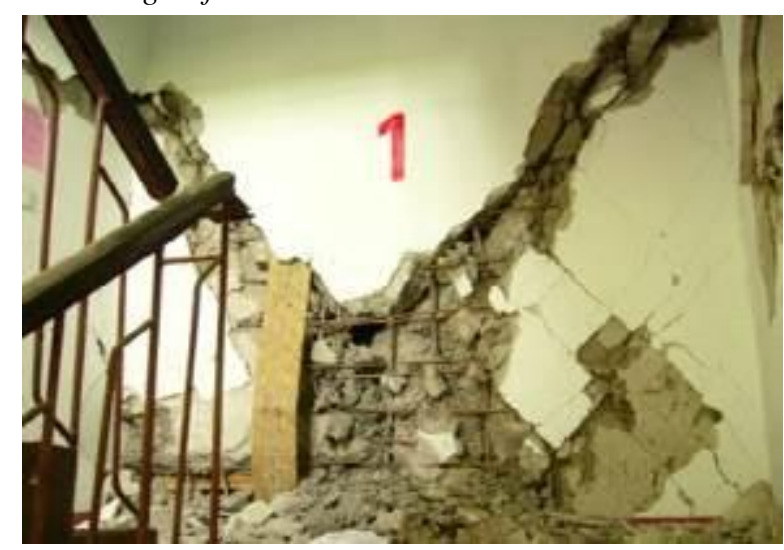

(a). Shear failure of reinforced concrete anti-seismic wall.

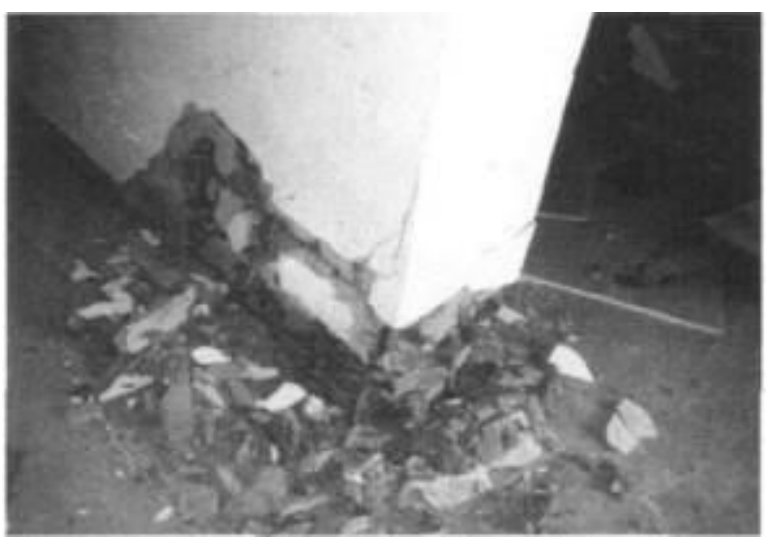

(b). Damage of wall corner.

Figure 1. Damage of reinforced concrete aseismic wall.

Based on the theory of multi-aseismic resistance and in order to ensure the ductility and shear capacity of the bottom frame shear layer, the bottom frame structures are required to set up reinforced concrete wall along the vertical and horizontal at the bottom layer according to 
current seismic code. During the seismic design stage, the anti-seismic walls are designed to bear all the earthquake shear force. Seismic damage of reinforced concrete shear wall in the actual damage scene is relatively rare, the main reas on is the strength and stiffness of shear walls are great, and it is not easy to result in obvious damage. However, when the seismic peak acceleration is large or the aspect ratio is too small, the shear failure will occur because of the earthquake shear, which the reinforced concrete shear wall is subjected over its limit bearing capacity (Fig. 1). The destruction of the shear wall consumes the energy of the earthquake and protects the main structure, which is regarded as the first defending line of the bottom frame structure ${ }^{[2]}$.

The common brick masonry anti-seismic wall was used in previous bottom frame structure. However, due to the low shear strength, poor ductility and brittle failure of the masonry (Fig. 2), the current seismic code ${ }^{[3]}$ provisions that only the total floor number of bottom frame structure does not exceed four can use common brick masonry antiseismic wall in 6 intensity section. And the mixed use of reinforced concrete anti-seismic wall and brick aseismic wall in the same direction is not allowed. The reason is that the material properties of these two anti-seismic walls are very different, and preventing the defeat in detail under the earthquake action causes adverse effects on the main structure.

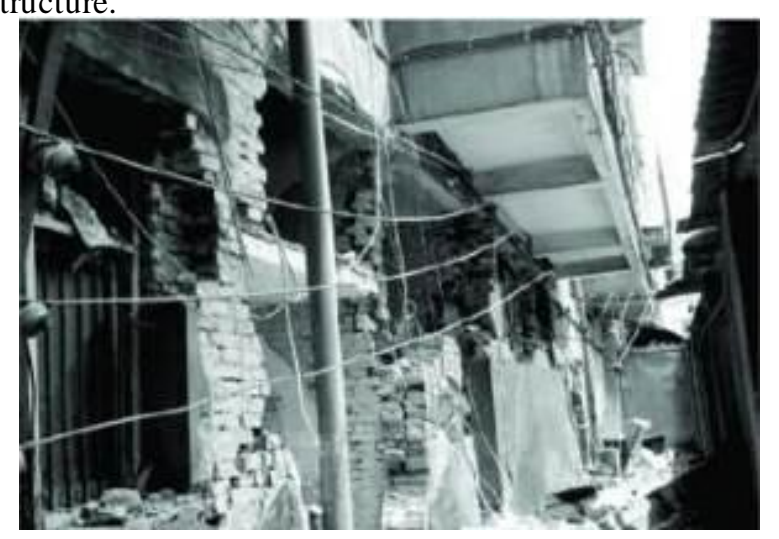

(a) Damage of masonry anti-seismic wall in longitudinal direction

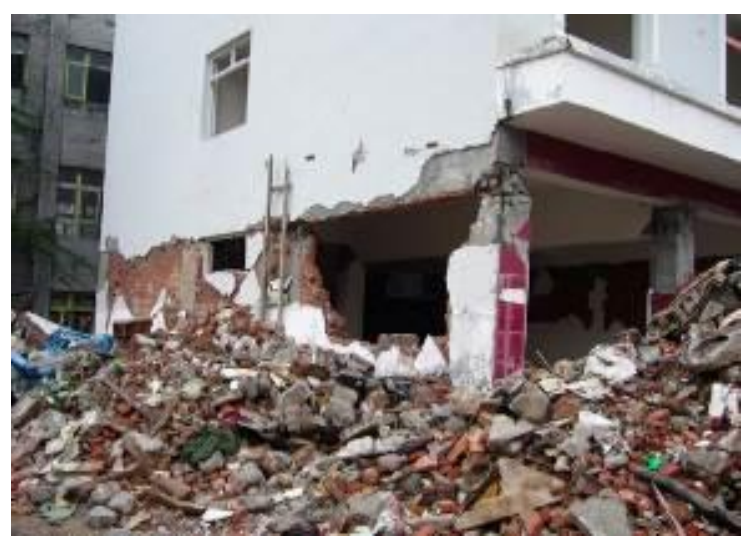

(b) Damage of masonry anti-seismic wall in horizontal direction.

Figure 2. Damage of brick aseismic wall.

\section{B. Damage offrame columns}

When the failure occurs on the bottom frame columns, almost all the plastic failures appear to be column cap and column base, rarely appears to ductile failure of beams. At the highest bending stresses of concrete column, the concrete of column cap is crushed and shedding, steel bar occur severe deformation of the bending and twisting. The more serious damage to the columns of bottom frame structures lead to tilt, fracture and collapse of the bottom layer directly. Sometimes, due to the setting of infilled walls in the bottom layer, it will produce additional shear and additional bending moment to the frame columns which causes the shear failure or bending failure (Fig. 3).

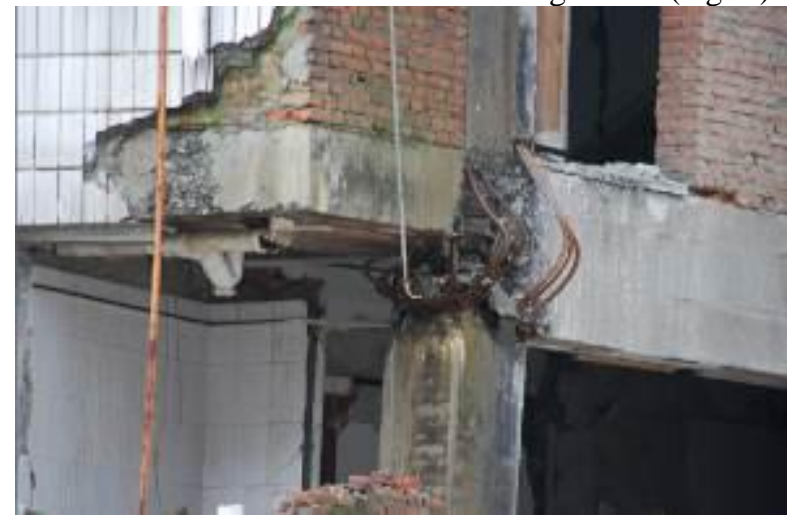

(a) Compressional buckling of steel bar of column.

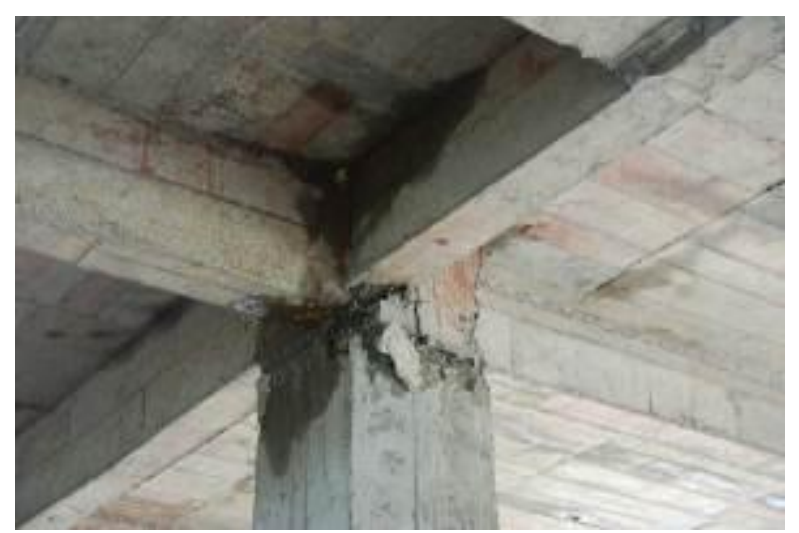

(b) Plastic hinge appears in beam-column joint.

Figure 3. Damage of frame column.

\section{Collapse of the bottom layer}

For structure buildings, the earthquake shear of the bottom layer is the largest. When the earthquake acceleration peak is higher, and there is no aseismic wall in the bottom layer or the quantity of aseismic walls are few, the bottom frame-shear wall stories appears obvious interlayer displacement after entering the elastic-plastic deformation. When the deformation exceeds a certain threshold, the stiffness of bottom anti-seismic wall degenerates greatly and frame bears larger earthquake force. The failure of beam-column joint and eventually leads to the serious damage of bottom layer or even collapse (Fig. 4). 


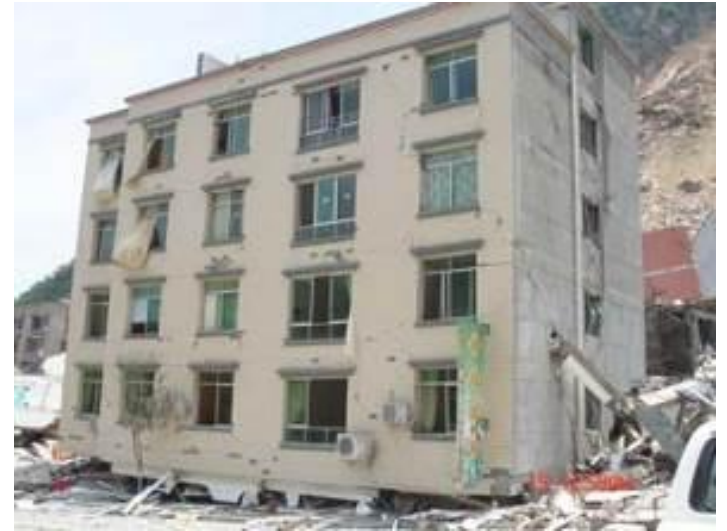

(a) Collapse of the bottom layer.

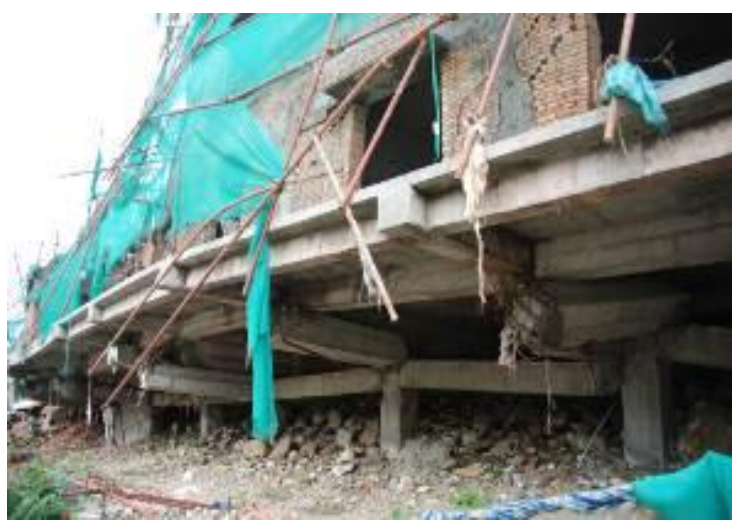

(b) Collapse of the bottom layer.

Figure 4. Collapse of the bottom layer.

\section{DAMAGE OF THE TRANSIT ION LAYER}

The lateral stiffness of the transition layer is changed dramatically, which is easy to produce stress concentration. In addition to bearing the earthquake shear force, the transition layer also needs to bear the overturning moment of the upper layers. The force is more complex, so it usually gets most serious damage during the earthquake. When the horizontal earthquake shear force exceeds the bearing capacity of the transition layer, the "sitting layer" phenomenon of the whole transition layer under the weight force of the upperstructure is more common (Fig. 5).

Comparing with the collapse of the bottom layer, the reas on of the "sitting layer" phenomenon of the whole transition layer is that much more anti-seismic walls or infill walls are set in the bottom layer. So that the stiffness and shear strength of bottom layer is large, that causes the weak floor of the structure transfers from the bottom layer which has better ductility and energy dissipation capacity to transition layer. That results in serious damage to the walls of the transition layer. So the difference of material properties is considered by seismic code ${ }^{[4]}$, and the rigidity of the bottom layer is required to be lower than the transition layer. However in the actual seis mic damage, the damage to the walls of the transition layers are very serious regardless of whether it is strictly according to the standard design. That means the stress of transition layer is complex, the seismic mechanism of the transition layer needs further analysis and more reasonable design index needs to be researched.

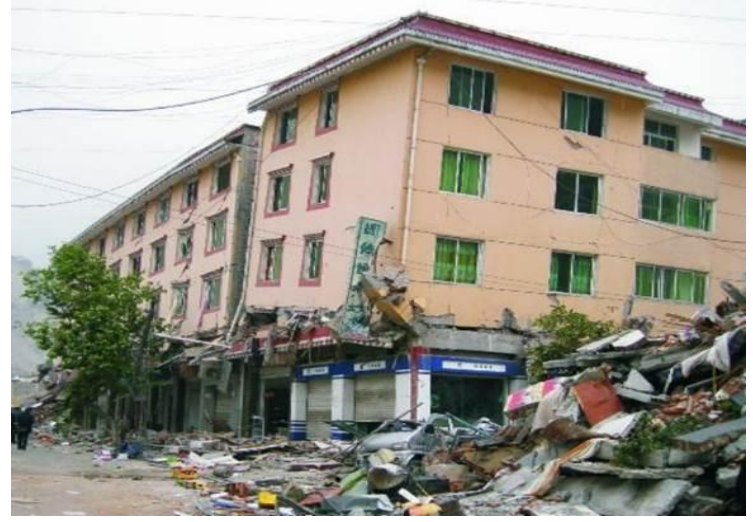

(a) Damage of the transition layer.

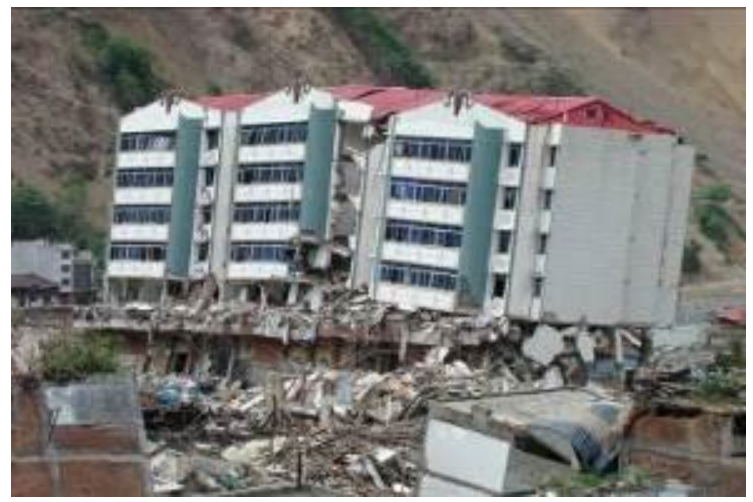

(b) Damage of the transition layer.

Figure 5. Damage of the transition layer.

\section{DAMAGE OF UPPER MASONRY LAYERS}

\section{A. Damage of wall between windows and allege}

The failure characteristics of the upper masonry layers of bottom frame structures are similar to the multistory masonry structures ${ }^{[5]}$. The main failure characteristics including wall cracking, shear inclined cracks, cracks in $\mathrm{X}$ crossover type, horizontal and vertical cracks. One of the common damage is the destruction of the wall between windows. wall between windows Because of poor integrity, low bearing capacity and window and door openings produce stress concentration, these reasons lead to wall between windows often appear shear inclined cracks or cross X type crack (Fig. 6).

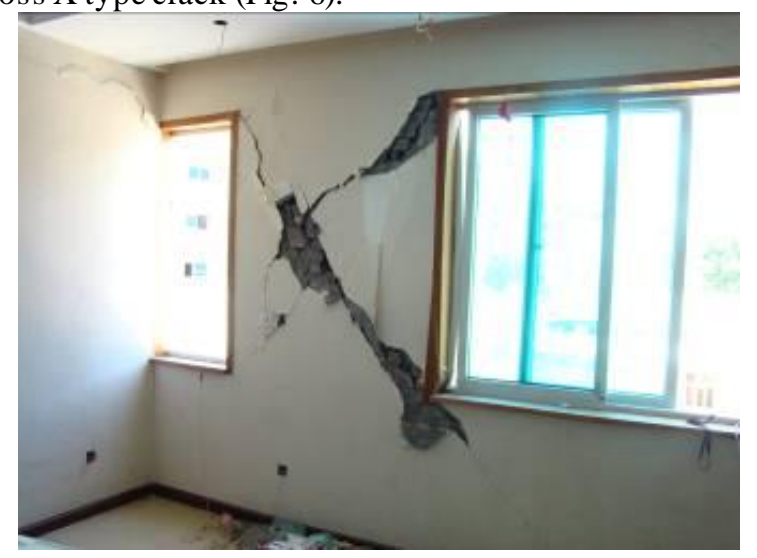

(a) Inclined cracks in wall between windows(internal). 


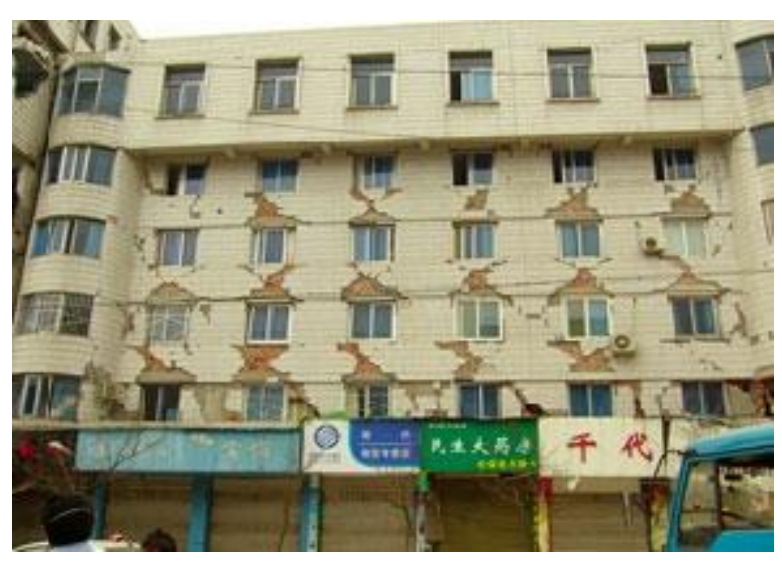

(b) Damage of the wall under windows in upper masonry layers.

Figure 6. Damage of wall between windows and allege.

\section{B. Collapse of upper masonry layers}

The bottom frame shear layer is damaged lightly, but the upper masonry layers are severely damaged or collapsed. The reason is that much more anti-seismic walls or infill walls are set in the bottom layer, so the stiffness and shear strength of bottom layer is large, that causes the weak floor of the structure transfers from the bottom layer to the upper masonry layers. The tensile strength and shear strength of masonry structures are very low, and the ductility is poor, it is easy to be brittle failure under the horizontal earthquake action. When the walls of upper masonry layers are less and the earthquake peak acceleration is very large, it will cause wall cracks because of the deficiency of anti-collapse ability, and even cause the collapse of the overall structure (Fig. 7).

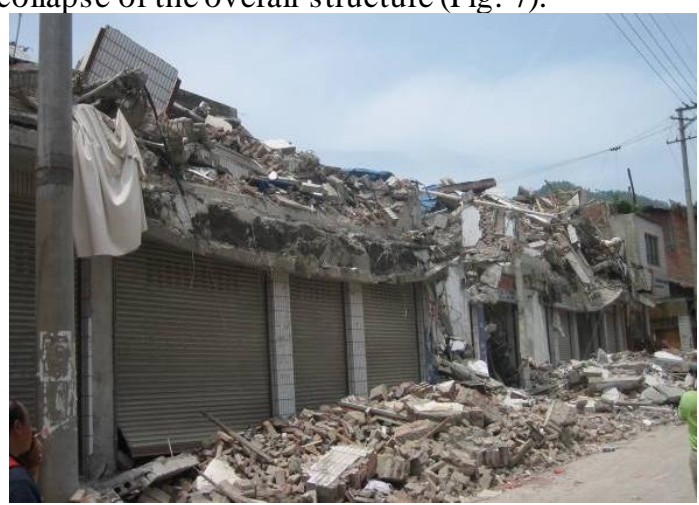

(a). Collapse of upper masonry layers.

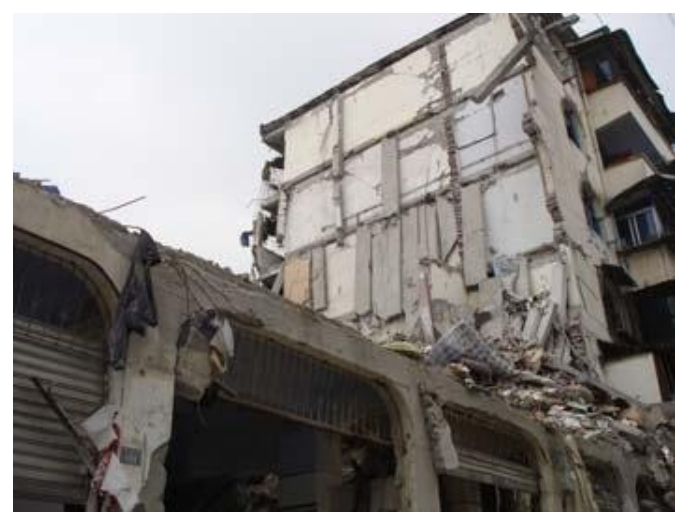

(b). Collapse of upper masonry layers.

Figure 7. Collapse of upper masonry layers.

\section{CONCLUSIONS AND SUGGESTIONS}

Based on the composition characteristics of the bottom frame structure, combined the failure mode of bottom frame structure in high intensity area during the "5.12" Wenchuan earthquake, the characteristics of earthquake damages are summarized from the aspects on bottom frame column, anti-seismic walls, transition layer and upper masonry layers. The reasons of damage are analy zed, and the following suggestions are put forward:

Firstly, the lateral stiffness ratio of the structure should be strictly controlled, and the uniform damage should be guided for the whole structure. The emergence of obvious weak floors should be avoided. The ductility and energy dissipation capacity of the bottom shear layer are better, and the bottom frame shear layer should be used as the main energy dissipation floor.

Secondly, much more attention should be paid to multi-aseismic resistance during the seismic design. The reinforced concrete anti-seismic wall in bottom layer of bottom frame structure should be considered as the first defending line of structure. In the initial stage of the earthquake, the anti-seismic wall bear most of the seismic shear, and when it is damage inactivation the frame column still can ensure to undertake according to the rigid ity distribution corres ponding to the ratio of the shear. This is the second defending line of the bottom frame structure. In the upper masonry layers, the brick wall is considered as the first defending line in the initial stage of the earthquake which is the main load-bearing component. When the thorough crevice appears to the walls, constructional column and the ring beam are considered as a second line of defense which is similar to the frame structure system, in order to ensure the integrity of the upper masonry layers.

Thirdly, the walls of transition layer should be strengthened. The actual earthquake damage shows that the damage to the walls of the transition layers are very serious regardless of whether it is strictly according to the standard design. The walls of transition layers locate in the region which has complex stress and vertical stiffness changes violently. Therefore, it is suggested that the level of masonry mortar should be increased, the number of constructional column should be increased, and the connection measures between the wall and the construction column and ring beam should be strengthened.

\section{REFERENCES}

[1] B. X. Li and Z. Wang, "Lessons from the performance of masonry structure with ground RC frame during Wenchuan earthquake," Journal of Zhongshan University, vol. 49(2), 2010, pp. 22-27.

[2] J. Q. Lin, Y. S. Chen and J Wang, "Analysis of seismic damage to highway bridges in Mianzhu City during Wenchuan Ms 8.0 earthquake," World Earthquake Engineering, vol. 26(1), 2010, pp. 80-85.

[3] GB 50011-2010. "Code for seismic design of buildings," China Architecture \& Building Press, Beijing, 2010.

[4] JGJ 248-2012. "Technical specification for earthquake resistant of masonry buildings with frame and seismic wall in the lower stories," China Architecture \& Building Press, Beijing, 2012.

[5] L. H. Xiong, X. L. Du and M. Lu. "Damage of multistory building during the 2008 Wenchuan earthquake," Journal of Beijing university of technology, vol. 34(11),2008, pp. 1167-1172. 